\title{
An EPQ Inventory Model with Allowable Shortages for Deteriorating Items under Trade Credit Policy
}

\author{
Zohreh Molamohamadi, ${ }^{1}$ Rahman Arshizadeh, ${ }^{2}$ and Napsiah Ismail ${ }^{1}$ \\ ${ }^{1}$ Department of Mechanical and Manufacturing Engineering, Universiti Putra Malaysia, Selangor 43300, Malaysia \\ ${ }^{2}$ Department of Computer Engineering, Science and Research Branch, Islamic Azad University, Tehran 1477893855, Iran \\ Correspondence should be addressed to Zohreh Molamohamadi; zmmohamadi@gmail.com
}

Received 2 December 2013; Revised 14 January 2014; Accepted 14 January 2014; Published 24 February 2014

Academic Editor: Juan J. Nieto

Copyright (c) 2014 Zohreh Molamohamadi et al. This is an open access article distributed under the Creative Commons Attribution License, which permits unrestricted use, distribution, and reproduction in any medium, provided the original work is properly cited.

\begin{abstract}
This paper attempts to obtain the replenishment policy of a manufacturer under EPQ inventory model with backorder. It is assumed here that the manufacturer delays paying for the received goods from the supplier and the items start deteriorating as soon as they are being produced. Based on these assumptions, the manufacturer's inventory model is formulated, and cuckoo search algorithm is applied then to find the replenishment time, order quantity, and selling price with the objective of maximizing the manufacturer's total net profit. Besides, the traditional inventory system is shown as a special case of the proposed model in this paper, and numerical examples are given to demonstrate better performance of trade credit. These examples are also used to compare the results of cuckoo search algorithm with genetic algorithm and investigate the effects of the model parameters on its variables and net profit.
\end{abstract}

\section{Introduction}

In the traditional inventory systems, it was assumed that the buyer pays the vendor as soon as he receives the items. In real-world situation, however, there are some cases that the vendor allows the buyer to defer payment. As Piasecki [1] and Molamohamadi et al. [2] state, four types of delay in payment can be considered; paying as sold, paying as sold after a predefined period, paying after a predefined period, and paying at the end of replenishment period (for more information, please refer to $[1,2])$.

In the third mentioned type of delay in payment, which is the concern of this paper, the payment is deferred until an agreed-upon period, so-called credit period. During the credit period, no interest is charged by the vendor and the buyer can sell the goods and accumulate revenues to earn interest. However, a high interest would be charged, if the payment is not settled by the buyer at the end of the delay period.

Such a contract has some benefits to the vendor and the buyer. The buyer can sell the items and earn interest before the payment is settled. Moreover, as the buyer may order more quantities under trade credit contract, his purchasing cost, replenishment cost, and backorder cost may decrease, while inventory holding cost and deterioration cost of the goods would increase. In addition, the vendor can apply trade credit as a strategic policy to be able to compete in the global competitive market in attracting more buyers and selling more products.

This clarifies the importance of finding the optimal ordering policy of the vendor and the buyer under trade credit contract to increase/decrease their revenue/cost. In order to find the literature gap, this section expresses the major concern of the precedent researches. Haley and Higgins [3] evaluated the inventory policy of a two-part trade credit, where the vendor considers cash discount for paying within a specified period and due in a larger credit period. Goyal [4] obtained the economic order quantity under the conditions of permissible delay in payments.

Aggarwal and Jaggi [5] considered deteriorating items to develop Goyal [4] and further assumed that the sales revenue is also accumulated beyond the delay period. Later, Jamal et al. [6] generalized Aggarwal and Jaggi [5] to allow for shortages. Sarker et al. [7] generalized Jamal et al. [6] by developing an EOQ inventory model for deteriorating items with allowable shortages and time value of money. Chang 
and Dye [8] extended Aggarwal and Jaggi [5] to the case of varying deterioration rate and partial backorder. Teng [9] modified Goyal's [4] model by setting different purchase cost and selling price. Having applied an EPQ model, Chung and Huang [10] generalized Goyal's [4] model to the finite replenishment rate. Huang [11] developed a two-level trade credit to reflect the real-life business condition and to extend Goyal [4]. Two-level trade credit is a kind of contract in which not only the vendor allows the buyer to defer payment, but also the buyer offers a credit period to his customers.

Chang et al. [12] extended Teng's [9] model to include deteriorating items, time-dependent demand, and orderdependent trade credit. Chang and Teng [13] developed Goyal's [4] model by assuming deterioration rate and cash discount and compared it with the traditional EOQ inventory system. Teng et al. [14] proposed an EOQ model with deteriorating items, price sensitive demand, and different selling and purchasing prices under trade credit policy and finally discussed the results obtained by Goyal [4], Aggarwal and Jaggi [5], and Jamal et al. [6]. Considering different selling and purchasing values, Huang [15] further extended Goyal's [4] model to the case of partial trade credit.

Ouyang et al. [16] developed Teng [9] by assuming deteriorating items and partial backlogging. Chen and Ouyang [17] fuzzified the time parameters of Jamal et al's [6] model and compared the findings with theirs. Ouyang et al. [18] established an EOQ model for noninstantaneous deteriorating items under permissible delay in payment to generalize some previous studies including Goyal [4] and Teng [9]. Huang [19] generalized Huang [11] and Chung and Huang [10] by formulating an EPQ model under a two-level trade credit where the purchasing cost and the selling price are not necessarily equal. Huang's [11] model was also developed by Liao [20] where an EPQ model for deteriorating items with different selling and purchasing prices was considered.

Chung and Huang [21] generalized Goyal's [4] model to obtain the optimal ordering policy in an EOQ model with allowable shortages. Hu and Liu [22] developed Chung and Huang [21] to an EPQ model with backorder where the purchasing cost is smaller than the selling price. Min et al. [23] addressed an EOQ inventory system for deteriorating items with stock-dependent demand under two levels of trade credit and concluded Goyal [4] and Huang [11] as special cases of their model. Chung [24] generalized Chung and Huang [10] and Huang [11] by formulating an EPQ inventory system under two levels of trade credit, different selling and purchasing prices, and limited storage capacity.

Lin et al. [25] presented an integrated inventory model consisting of a vendor and a buyer under a two-level trade credit with credit-sensitive demand and defective items. Teng et al. [26] obtained the optimal order quantity and cycle time of an EOQ inventory system with time-sensitive demand and permissible delay in payment. Guchhait et al. [27] investigated the effect of partial trade credit on retailer's order quantity, where two warehouses are assumed, and proposed a hybrid metaheuristic algorithm to obtain the solution. Taleizadeh et al. [28] established an EOQ inventory model with partial trade credit and partial shortages to find the optimal shortage level and replenishment decisions.
From an integrated inventory model with price-sensitive demand, deterioration rate, and allowable shortages, $\mathrm{Yu}$ [29] concluded that vendor-buyer collaboration would lead to extra profit gain. He and Huang [30] incorporated Ouyang et al. [18] and Jaggi et al. [31] by developing an EOQ inventory model for noninstantaneous deteriorating items under a twolevel trade credit policy.

Studying the literature shows that most of the studies of trade credit have considered EOQ inventory system. Moreover, during the past decades, deteriorating items have captured many researchers' attention. Generally, all of the 2 products deteriorate over time [20]. For some items such as toys, glassware, and hardware, deterioration rate is too low and can be neglected. For others such as medicines, electronic items, volatile liquids, blood banks, and fashion goods, high deterioration rate can significantly affect decision making. So, this paper establishes a trade credit inventory model for deteriorating items within the EPQ framework, where the replenishment rate is finite. The buyer is a manufacturer in this paper, who is offered trade credit by the supplier (vendor). It is assumed that the purchasing cost of the manufacturer is not necessarily equal to his selling price. Moreover, as stockout is an inevitable consequence of diverse uncertainties, the shortages are allowed here. Since the analytical solving of the model is difficult, the proposed model is solved by cuckoo search algorithm, introduced in 2009 by Yang and Deb [32], to obtain the proper values of replenishment cycle, order quantity, and selling price, in a way that the manufacturer's net profit is maximized. Finally, by applying numerical examples, the sensitivity of the variables to the parameters is tested and the performance of the cuckoo search algorithm is compared with genetic algorithm, whose usual form was introduced by Goldberg in 1989 [33]. Deducing traditional inventory system, where there is no delay in payment, as a special case of the formulated model in this paper, its profitability to the manufacturer is compared with trade credit.

The rest of this paper is organized as follows. Section 2 introduces the notations and assumptions used in formulating the inventory system. The manufacturer's inventory model is formulated in Section 3 and the solution procedure is explained in Section 4. Section 5 gives a numerical example to investigate the sensitivity of the model to the parameters, compares the performance of cuckoo search algorithm with genetic algorithm, and examines the difference between one-level trade credit and the traditional inventory system. Finally, the conclusion is discussed in Section 6 and some opportunities for future researches are mentioned.

\section{Notations and Assumptions}

For modeling the inventory system of the manufacturer, we will use the following notations and assumptions throughout this paper.

2.1. Notations. The following symbols are applied to model the manufacturer's inventory system:

$D$ : The demand rate 
$k$ : A constant in the demand function representing the market scale

$\alpha$ : The price elasticity of the demand rate

$P$ : The replenishment rate

$\rho$ : The capacity utilization

$\theta$ : The deteriorating rate, a fraction of the on-hand inventory

$A$ : The ordering and setup cost per cycle

$h_{m}$ : The inventory holding cost rate, excluding interest charges

$I_{p}$ : The opportunity cost per dollar

$I_{e}$ : The interest earned per dollar

$M$ : The trade credit period offered by the supplier

$b$ : The backorder level

$c_{b}$ : The backorder cost

$s$ : The unit purchasing cost

$v$ : The unit selling price

$I(t)$ : The inventory level at time $t$

$T_{1}$ : The production time with backorder

$T_{2}$ : The production time when positive stock builds up and the stock depletes due to the demand and deterioration

$T_{3}$ : The time period when the stock depletes due to the demand and deterioration

$T_{4}$ : The time period with no replenishment, when the shortages occur

$T$ : The replenishment time, $T=T_{1}+T_{2}+T_{3}+T_{4}$

$Q$ : The economic order quantity.

\subsection{Assumptions}

(1) The demand rate is a decreasing function of the manufacturer's selling price $(v)$ and is defined by $k v^{-\infty}$. Actually, the demand is a dependent variable whose value is sensitive to the selling price. This assumption is considered to include the effect of the competitive market, where, besides delay in payment, selling price is one of the key factors for customers in deciding from which manufacturer to buy.

(2) The time horizon is infinite.

(3) The time of product deterioration follows an exponential distribution with parameter $\theta$, where $0<\theta \ll$ 1. There is no repair or replacement of deteriorated units during the planning horizon. It is assumed that deterioration starts when the products are stored at the manufacturer's warehouse.

(4) The supplier proposes a certain credit period, $M$, to the manufacturer. During the credit period, the manufacturer can accumulate revenue and earn interest with rate $I_{e}$, by selling the products to his customers. At the end of the credit period, the manufacturer

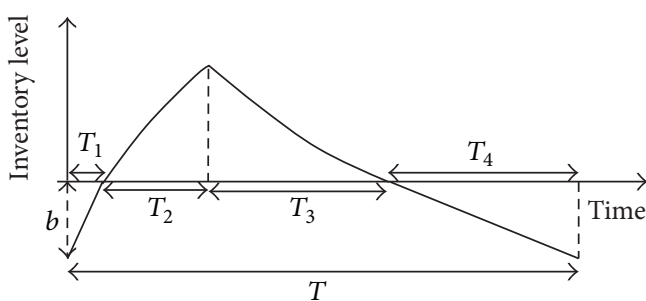

FIGURE 1: The inventory level of the manufacturer.

settles the account and incurs a capital opportunity cost at rate $I_{p}$ for the items still in his stock.

(5) Shortages are allowed and are fully backlogged. So, if the manufacturer has inventory on hand, he delivers the products to the customers at the time of placing the orders. Otherwise, he defers the delivery to the next period.

(6) Inventory holding cost is charged only on the amount of undecayed stock.

(7) $I_{p} \geq I_{e}$ and $v>s$.

(8) The manufacturer's capacity utilization, $\rho$, is the ratio of the demand rate to the production rate and is less than 1; that is, $\rho=D / P<1$.

(9) The manufacturer aims at maximizing his net profit by determining the optimal selling price, replenishment cycle, and quantity of orders.

\section{Formulating the Inventory Model}

Figure 1 depicts the inventory level of the manufacturer in an EPQ-based inventory model with allowable shortages and deteriorating items.

It is necessary to mention that, during the first period $\left(T_{1}\right)$, the manufacturer produces items to satisfy the arriving demands as well as the previous period's backlogged demands. This means that the line below the axis is for showing that the manufacturer does not keep any item in stock as they must be delivered to the customers. Moreover, in $T_{4}$, there is not any product to satisfy the customers' demands and the graph below the axis illustrates the demands which are going to be backlogged to the next period.

For formulating the inventory system, we must firstly obtain the inventory level function at any time $t$.

(1) The Inventory Level in $T_{1}\left(0 \leq t \leq T_{1}\right)$. The produced items during 0 to $T_{1}$ would be depleted due to the instant demand $(D)$ as well as backlogged orders. As a result, the differential equation representing the inventory position of the system at time $t, 0 \leq t \leq T_{1}$, is

$$
\frac{d I_{1}(t)}{d t}=P-D
$$

Using the boundary condition $I_{1}\left(T_{1}\right)=0$, the solution of (1) is

$$
I_{1}(t)=-(P-D)\left(T_{1}-t\right), \quad 0 \leq t \leq T_{1}
$$


(2) The Inventory Level in $T_{2}\left(T_{1} \leq t \leq T_{1}+T_{2}\right)$. In $T_{2}$, the inventory increases with rate $P$ and decreases due to customers' demand and deterioration. Hence, the inventory level in this period can be described by (3)

$$
\frac{d I_{2}(t)}{d t}=P-D-\theta I_{2}(t), \quad T_{1} \leq t \leq T_{1}+T_{2} .
$$

With $I_{2}\left(T_{1}\right)=0$ as the initial condition, solving (3) yields

$$
I_{2}(t)=\frac{(P-D)}{\theta}\left(1-e^{-\theta\left(t-T_{1}\right)}\right), \quad T_{1} \leq t \leq T_{1}+T_{2} .
$$

(3) The Inventory Level in $T_{3}\left(T_{1}+T_{2} \leq t \leq T_{1}+T_{2}+T_{3}\right)$. The inventory depletes in this period by the demand and deterioration. Thus, the inventory level in $T_{3}$ is governed by the subsequent differential equation

$$
\frac{d I_{3}(t)}{d t}=-D-\theta I_{3}(t), \quad T_{1}+T_{2} \leq t \leq T_{1}+T_{2}+T_{3}
$$

with the boundary condition $I_{3}\left(T_{1}+T_{2}+T_{3}\right)=0$. So, the inventory level at $T_{3}$ is

$$
I_{3}(t)=\frac{D}{\theta}\left(e^{\theta\left(T_{1}+T_{2}+T_{3}-t\right)}-1\right), \quad T_{1}+T_{2} \leq t \leq T_{1}+T_{2}+T_{3} .
$$

(4) The Inventory Level in $T_{4}\left(T_{1}+T_{2}+T_{3} \leq t \leq T\right)$. From $T_{1}+T_{2}+T_{3}$ to $T$, the manufacturer would have no inventory on hand and any demand in this period would be completely backlogged to the next replenishment cycle. Thus, the inventory level at $T_{4}$ satisfies the following differential equation:

$$
\frac{d I_{4}(t)}{d t}=-D, \quad T_{1}+T_{2}+T_{3} \leq t \leq T
$$

Considering $I_{4}\left(T_{1}+T_{2}+T_{3}\right)=0$ as the initial condition, the inventory level at this period is

$$
I_{4}(t)=-D\left(t-\left(T_{1}+T_{2}+T_{3}\right)\right), \quad T_{1}+T_{2}+T_{3} \leq t \leq T .
$$

Besides the aforementioned functions of the inventory levels, the following relationships can be concluded from Figure 1.

(i) The manufacturer's economic order quantity $(Q)$ equals $P\left(T_{1}+T_{2}\right)$.

(ii) Since $b=(P-D) T_{1}=D T_{4}$, the relations between $T_{1}$ and $T_{4}$ can be represented by $T_{4}=(P-D) T_{1} / D$.

(iii) Moreover, from the fact that $I_{2}(t)=I_{3}(t)$ when $t=$ $T_{1}+T_{2}$, the relations between $T_{2}$ and $T_{3}$ can be shown as $T_{3}=(1 / \theta) \ln \left[\left((D-P) e^{-\theta T_{2}}+P\right) / D\right]$.

The manufacturer's inventory model consists of the selling revenue, replenishment cost, stock holding cost, backorder cost, deterioration cost, interest earned, and the opportunity cost. These elements are formulated below.
3.1. Selling Revenue. The manufacturer sells the produced items in $T_{1}$ and satisfies the customers' demands during $T_{2}$ and $T_{3}$. So, his revenue per period is $(v-s)\left[P T_{1}+D\left(T_{2}+T_{3}\right)\right]$ and consequently per unit time is $(v-s)\left[P T_{1}+D\left(T_{2}+T_{3}\right)\right] / T$.

3.2. Replenishment Cost. Considering $A$ as the manufacturer's ordering cost, his replenishment cost per unit time is A/T.

3.3. Stock Holding Cost. For formulating the manufacturer's inventory holding cost per period, the areas under $T_{2}$ and $T_{3}$ in Figure 1 must be calculated. Thus, for the stock holding cost per unit time, we have

$$
\begin{aligned}
\frac{s h_{m}}{T} & {\left[\int_{T_{1}}^{T_{1}+T_{2}} I_{2}(t) d t+\int_{T_{1}+T_{2}}^{T_{1}+T_{2}+T_{3}} I_{3}(t) d t\right] } \\
= & \frac{s h_{m}}{T \theta^{2}}\left[(P-D)\left(e^{-\theta T_{2}}-1+\theta T_{2}\right)+D\left(e^{\theta T_{3}}-1-\theta T_{3}\right)\right] \\
= & \frac{s h_{m}}{T \theta^{2}}\left[(P-D) \theta T_{2}-D \theta T_{3}\right] .
\end{aligned}
$$

3.4. Backorder Cost. The backorder cost is calculated based on the areas under $T_{1}$ and $T_{4}$ and its value per unit time is equal to

$$
\begin{aligned}
- & \frac{c_{b}}{T}\left[\int_{0}^{T_{1}} I_{1}(t) d t+\int_{T_{1}+T_{2}+T_{3}}^{T_{1}+T_{2}+T_{3}+T_{4}} I_{4}(t) d t\right] \\
& =\frac{c_{b}}{T}\left[\frac{T_{1}^{2}}{2}(P-D)+\frac{T_{4}^{2}}{2} D\right] .
\end{aligned}
$$

By considering the relations between $T_{1}$ and $T_{4}$, (10) can be reformulated as

$$
\begin{gathered}
\frac{c_{b}}{T}\left[\frac{T_{1}^{2}}{2}(P-D)+\frac{T_{1}^{2}}{2} \frac{(P-D)^{2}}{D}\right] \\
=\frac{c_{b}}{T}\left[\frac{T_{1}^{2}}{2}(P-D)\left(\frac{P}{D}\right)\right] .
\end{gathered}
$$

3.5. Deterioration Cost. The number of deteriorated items in $T$ equals the produced items in $T_{2}$ minus the demand in periods $T_{2}$ and $T_{3}$. Therefore, the deterioration cost per unit time can be represented as

$$
\frac{s}{T}\left[P\left(T_{2}\right)-D\left(T_{2}+T_{3}\right)\right]
$$

3.6. Interest Earned. The manufacturer earns interest from the time of receiving the items from the supplier until $M$, when he settles the account. Depending on the length of the credit period $(M)$, three cases may occur: (1) $M \leq T_{1}$, (2) $T_{1} \leq M \leq T_{1}+T_{2}+T_{3}$, and (3) $M \geq T_{1}+T_{2}+T_{3}$. Accumulation of interests and the inventory levels of these cases are explained here. 


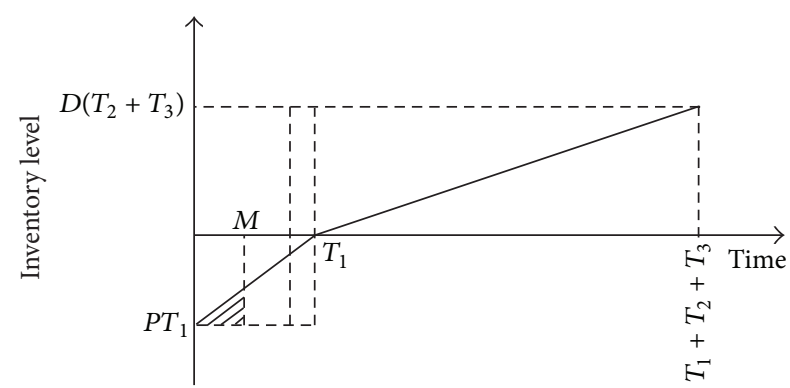

Figure 2: The total accumulation of interest earned when $M \leq T_{1}$.

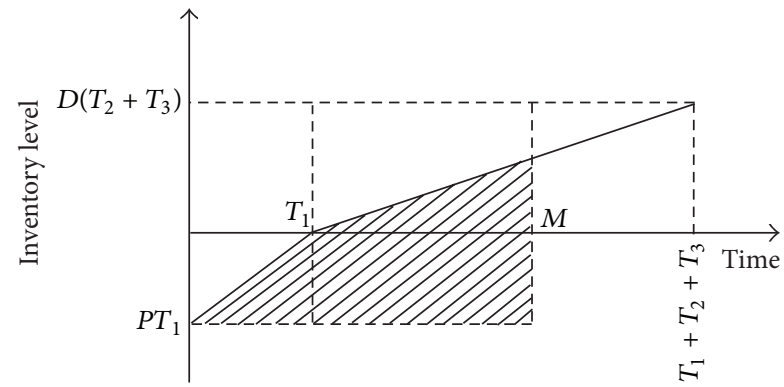

FIGURE 3: The total accumulation of interest earned when $T_{1} \leq M \leq$ $T_{1}+T_{2}+T_{3}$.

3.6.1. Case I: $M \leq T_{1}$. As shown in Figure 2 and by considering $v$ as the selling price and $I_{e}$ as the interest earned per monetary unit, the manufacturer's interest earned per unit time in this case is

$$
\frac{v I_{e}}{T}\left[P M T_{1}-\left(-\int_{0}^{M} P\left(t-T_{1}\right) d t\right)\right]=\frac{v I_{e}}{T}\left(\frac{P M^{2}}{2}\right)
$$

3.6.2. Case II: $T_{1} \leq M \leq T_{1}+T_{2}+T_{3}$. According to Figure 3, the manufacturer's earned interest per unit time follows

$$
\begin{aligned}
& \frac{v I_{e}}{T}\left[-\int_{0}^{T_{1}} P\left(t-T_{1}\right) d t+\left(M-T_{1}\right)\left(P T_{1}\right)+\int_{T_{1}}^{M} D\left(t-T_{1}\right)\right] \\
& \quad=\frac{v I_{e}}{T}\left[\frac{P T_{1}^{2}}{2}+\left(M-T_{1}\right)\left(P T_{1}\right)+\frac{D}{2}\left(M-T_{1}\right)^{2}\right] .
\end{aligned}
$$

3.6.3. Case III: $M \geq T_{1}+T_{2}+T_{3}$. Following Figure 4 , the interest earned per unit time for this case can be represented in

$$
\begin{aligned}
& \frac{v I_{e}}{T}\left[-\int_{0}^{T_{1}} P\left(t-T_{1}\right) d t+\left(M-T_{1}\right)\left(P T_{1}\right)\right. \\
& +\int_{T_{1}}^{T_{1}+T_{2}+T_{3}} D\left(t-T_{1}\right) \\
& \left.\quad+D\left(T_{2}+T_{3}\right)\left[M-T_{1}-T_{2}-T_{3}\right]\right]
\end{aligned}
$$

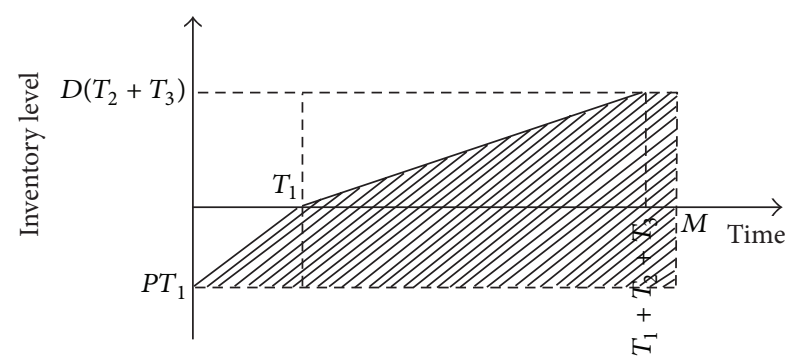

FIgURE 4: The total accumulation of interest earned when $M \geq T_{1}+$ $T_{2}+T_{3}$.

$$
\begin{gathered}
=\frac{v I_{e}}{T}\left[\frac{P T_{1}^{2}}{2}+\left(M-T_{1}\right)\left(P T_{1}\right)+\frac{1}{2} D\left(T_{2}+T_{3}\right)^{2}\right. \\
\left.+D\left(T_{2}+T_{3}\right)\left[M-T_{1}-T_{2}-T_{3}\right]\right]
\end{gathered}
$$

3.7. Interest Payable. Assuming that the manufacturer defers payment to $M$, he bears opportunity cost for the unsold items in his stock after $M$, and four cases must be assumed.

3.7.1. Case $I: M \leq T_{1}$. In this case, the opportunity cost/interest payable per unit time must be formulated as

$$
\begin{aligned}
& \frac{s I_{p}}{T}\left[\int_{T_{1}}^{T_{1}+T_{2}} I_{2}(t) d t+\int_{T_{1}+T_{2}}^{T_{1}+T_{2}+T_{3}} I_{3}(t) d t\right] \\
& \quad=\frac{s I_{p}}{T}\left[\frac{(P-D)}{\theta} T_{2}-\frac{D T_{3}}{\theta}\right] .
\end{aligned}
$$

3.7.2. Case II: $T_{1} \leq M \leq T_{1}+T_{2}$. The interest payable for this case is

$$
\begin{gathered}
\int_{M}^{T_{1}+T_{2}} I_{2}(t) d t+\int_{T_{1}+T_{2}}^{T_{1}+T_{2}+T_{3}} I_{3}(t) d t \\
=\frac{s I_{p}}{T}\left[-\frac{(P-D)}{\theta^{2}}\left(M \theta+e^{-\theta\left(M-T_{1}\right)}-\theta\left(T_{1}+T_{2}\right)\right)\right. \\
\left.\quad+\frac{P}{\theta^{2}}+\frac{D}{\theta^{2}}\left(-1-\theta T_{3}\right)\right] .
\end{gathered}
$$

3.7.3. Case III: $T_{1}+T_{2} \leq M \leq T_{1}+T_{2}+T_{3}$. The opportunity cost per unit time for the on-hand stock after $M$ in this case is calculated in (18) as follows:

$$
\begin{aligned}
& \int_{M}^{T_{1}+T_{2}+T_{3}} I_{3}(t) d t \\
& \quad=\frac{s I_{p}}{T}\left[\frac{D}{\theta^{2}}\left(e^{\theta\left(T_{1}+T_{2}+T_{3}-M\right)}-1-\theta\left(T_{1}+T_{2}+T_{3}-M\right)\right)\right] .
\end{aligned}
$$

3.7.4. Case IV: $T_{1}+T_{2}+T_{3} \leq M$. In this case, since there is not any inventory on hand after $M$, the interest payable equals zero. 
Based on the above arguments, the total net profit of the manufacturer per unit time can be expressed as $N P=$ selling revenue - Replenishment cost - Stock holding cost Backorder Cost - Deterioration Cost + Interest earned Interest payable, and the four following cases must be considered:

$$
N P= \begin{cases}N P_{1}, & \text { if } M \leq T_{1}, \\ N P_{2}, & \text { if } T_{1} \leq M \leq T_{1}+T_{2}, \\ N P_{3}, & \text { if } T_{1}+T_{2} \leq M \leq T_{1}+T_{2}+T_{3}, \\ N P_{4}, & \text { if } T_{1}+T_{2}+T_{3} \leq M,\end{cases}
$$

where

$$
\begin{aligned}
& N P_{1}=\frac{(v-s)\left[P T_{1}+D\left(T_{2}+T_{3}\right)\right]}{T}-\frac{A}{T} \\
& -\frac{s h_{m}}{T \theta^{2}}\left[(P-D) \theta T_{2}-D \theta T_{3}\right] \\
& -\frac{c_{b}}{T}\left[\frac{T_{1}^{2}}{2}(P-D)\left(\frac{P}{D}\right)\right] \\
& -\frac{s}{T}\left[P\left(T_{2}\right)-D\left(T_{2}+T_{3}\right)\right] \\
& +\frac{v I_{e}}{T}\left(\frac{P M^{2}}{2}\right)-\frac{s I_{p}}{T}\left[\frac{(P-D)}{\theta} T_{2}-\frac{D T_{3}}{\theta}\right], \\
& N P_{2}=\frac{(v-s)\left[P T_{1}+D\left(T_{2}+T_{3}\right)\right]}{T}-\frac{A}{T} \\
& -\frac{s h_{m}}{T \theta^{2}}\left[(P-D) \theta T_{2}-D \theta T_{3}\right] \\
& -\frac{c_{b}}{T}\left[\frac{T_{1}^{2}}{2}(P-D)\left(\frac{P}{D}\right)\right] \\
& -\frac{s}{T}\left[P\left(T_{2}\right)-D\left(T_{2}+T_{3}\right)\right] \\
& +\frac{v I_{e}}{T}\left[\frac{P T_{1}^{2}}{2}+\left(M-T_{1}\right)\left(P T_{1}\right)+\frac{D}{2}\left(M-T_{1}\right)^{2}\right] \\
& -\frac{s I_{p}}{T}\left[-\frac{(P-D)}{\theta^{2}}\left(M \theta+e^{-\theta\left(M-T_{1}\right)}-\theta\left(T_{1}+T_{2}\right)\right)\right. \\
& \left.+\frac{P}{\theta^{2}}+\frac{D}{\theta^{2}}\left(-1-\theta T_{3}\right)\right], \\
& N P_{3}=\frac{(v-s)\left[P T_{1}+D\left(T_{2}+T_{3}\right)\right]}{T}-\frac{A}{T} \\
& -\frac{s h_{m}}{T \theta^{2}}\left[(P-D) \theta T_{2}-D \theta T_{3}\right] \\
& -\frac{c_{b}}{T}\left[\frac{T_{1}^{2}}{2}(P-D)\left(\frac{P}{D}\right)\right] \\
& -\frac{s}{T}\left[P\left(T_{2}\right)-D\left(T_{2}+T_{3}\right)\right]
\end{aligned}
$$

$$
\begin{aligned}
+ & \frac{v I_{e}}{T}\left[\frac{P T_{1}^{2}}{2}+\left(M-T_{1}\right)\left(P T_{1}\right)+\frac{D}{2}\left(M-T_{1}\right)^{2}\right] \\
& -\frac{s I_{p}}{T}\left[\frac { D } { \theta ^ { 2 } } \left(e^{\theta\left(T_{1}+T_{2}+T_{3}-M\right)}-1\right.\right. \\
& \left.\left.-\theta\left(T_{1}+T_{2}+T_{3}-M\right)\right)\right], \\
N P_{4}= & \frac{(v-s)\left[P T_{1}+D\left(T_{2}+T_{3}\right)\right]}{T}-\frac{A}{T} \\
& -\frac{s h_{m}}{T \theta^{2}}\left[(P-D) \theta T_{2}-D \theta T_{3}\right] \\
& -\frac{c_{b}}{T}\left[\frac{T_{1}^{2}}{2}(P-D)\left(\frac{P}{D}\right)\right] \\
& -\frac{s}{T}\left[P\left(T_{2}\right)-D\left(T_{2}+T_{3}\right)\right] \\
& +\frac{v I_{e}}{T}\left[\frac{P T_{1}^{2}}{2}+\left(M-T_{1}\right)\left(P T_{1}\right)+\frac{1}{2} D\left(T_{2}+T_{3}\right)^{2}\right. \\
& \left.+D\left(T_{2}+T_{3}\right)\left[M-T_{1}-T_{2}-T_{3}\right]\right]
\end{aligned}
$$

Moreover, we have $D=k v^{-\propto}, T_{4}=(P-D) T_{1} / D, T_{3}=$ $\ln \left[\left((D-P) e^{-\theta\left(T_{2}\right)}+P\right) / D\right] / \theta, T=T_{1}+T_{2}+T_{3}+T_{4}$, and $P=D / \rho$.

3.8. Special Case. Setting $M$ and consequently $I_{e}$ equal to zero, the model represents the traditional EPQ inventory model with backorder where the payments are settled promptly. In this case, $I_{p}$ implies the manufacturer's opportunity cost for keeping inventory. So, the traditional inventory model with backorder can be formulated as

$$
\begin{aligned}
N P_{\text {traditional }}= & \frac{(v-s)\left[P T_{1}+D\left(T_{2}+T_{3}\right)\right]}{T}-\frac{A}{T} \\
& -\frac{s\left(h_{m}+I_{p}\right)}{T \theta^{2}}\left[(P-D) \theta T_{2}-D \theta T_{3}\right] \\
& -\frac{c_{b}}{T}\left[\frac{T_{1}^{2}}{2}(P-D)\left(\frac{P}{D}\right)\right] \\
& -\frac{s}{T}\left[P\left(T_{2}\right)-D\left(T_{2}+T_{3}\right)\right] .
\end{aligned}
$$

\section{Solution Procedure}

Since analytical solving of the formulated nonlinear programming inventory model is difficult, we apply a metaheuristic algorithm, called cuckoo search algorithm to solve the problem and find the optimum values. Cuckoo search is a novel stochastic global search algorithm, introduced in 2009 by Yang. This promising algorithm is based on the aggressive reproduction behaviour of cuckoo birds, which lay 
TABLE 1: The obtained solutions by cuckoo search algorithm for Example 1.

\begin{tabular}{lccccc}
\hline$M$ (days) & $T$ (days) & Q (units) & $v(\$)$ & $D$ (units/year) & NP $(\$)$ \\
\hline 10 & 51.97 & 4328.51 & 30.02 & 30397.70 & 308091.80 \\
15 & 34.94 & 2912.51 & 30.00 & 30525 & 608251.64 \\
30 & 19.07 & 1594.40 & 29.94 & 3059 & 609669.48 \\
45 & 19.06 & 1597.55 & 29.89 & 30598.09 & 611172.25 \\
60 & 19.05 & 1600.71 & 29.84 & 30673.30 & 612676.25 \\
\hline
\end{tabular}

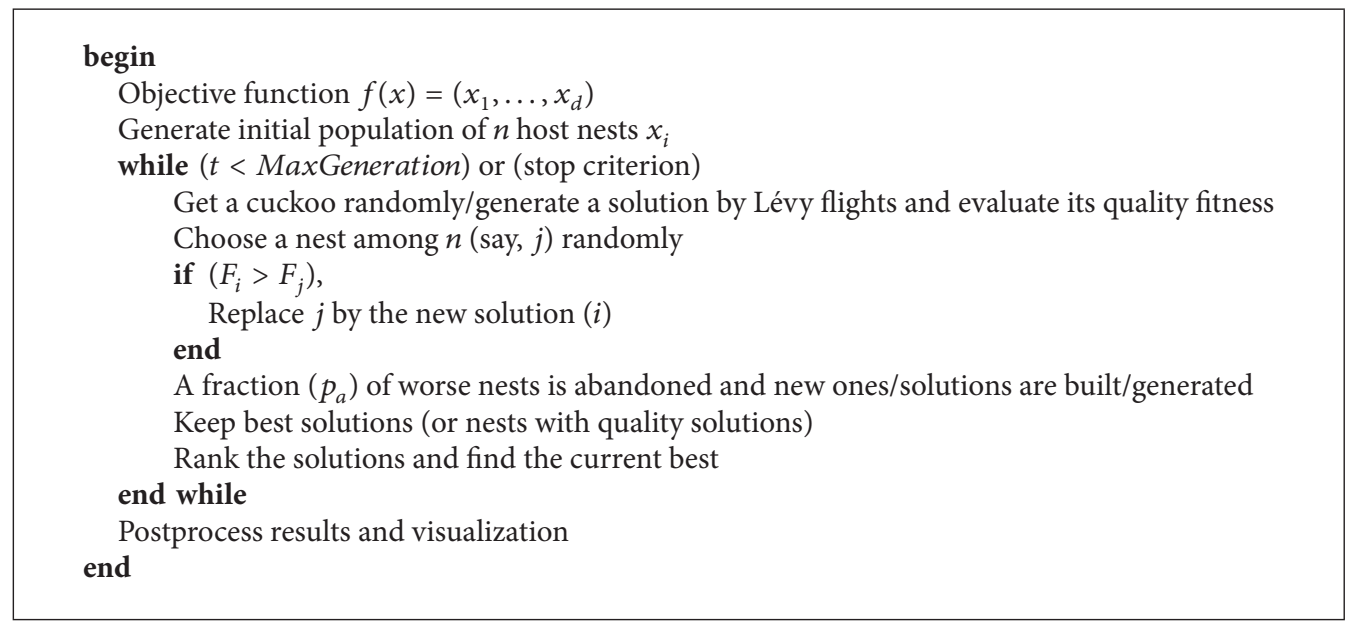

Algorithm 1: The pseudocode of the applied cuckoo search algorithm.

their eggs in the host birds' nests. The reason for applying cuckoo search algorithm in this paper is that (I), as Yang [34] mentioned, recent studies have demonstrated that cuckoo search algorithm is potentially far more effective than many other metaheuristic algorithms such as genetic and particle swarm optimization algorithms, and (II) according to Zhao and $\mathrm{Li}$ [35], cuckoo search algorithm has been successfully applied to both benchmark and real-world optimization problems.

Similar to other evolutionary algorithms, cuckoo search algorithm starts with an initial population of cuckoos with some eggs for laying in the nests of the host birds. The eggs with more similarity to the eggs of the host birds have more chances to survive and grow up, while some eggs would be either detected and killed by the host birds or abandoned in the nest. Moreover, the suitability of a nest is revealed by its grown eggs, and the best nests will survive to the next generation.

The following rules are applied in cuckoo search algorithm (Yang [34]).

(i) Each cuckoo lays one egg at a time and a nest is chosen randomly for dumping it.

(ii) The best nests are the ones with high quality eggs and would survive to carry over to the next generations.

(iii) There is a fixed number of host nests and if the laid egg is discovered with a probability $p_{a}\left(p_{a} \in[0,1]\right)$, the host bird may either throw it away or leave the nest to construct a completely new nest.
Considering $L_{i}$ and $U_{i}$ as the lower and upper bounds for decision variable $x_{i}$, the initial solutions for cuckoo search algorithm can be determined by

$$
x_{i}=L_{i}+\operatorname{rand}\left(U_{i}-L_{i}\right) .
$$

Moreover, the new solution for cuckoo $i, x_{i}(t+1)$, is generated by performing Lévy flight as shown in

$$
x_{i}(t+1)=x_{i}(t)+\alpha \oplus \operatorname{Lévy}(\lambda),
$$

where $\alpha>0$ is the step size and $\oplus$ represents entry-wise multiplication. The Lévy flight provides a random walk in which the random steps are drawn from a Lévy distribution with an infinite variance and mean;

$$
\text { Lévy } \sim u=t^{-\lambda}, \quad 1 \leq \lambda \leq 3 .
$$

Algorithm 1 represents the pseudocode of the applied cuckoo search algorithm.

\section{Numerical Examples}

Example 1. Following the examples provided by Ho [36], we consider an inventory system with the following data: $\rho=0.9$, $\theta=0.1, A=\$ 50 /$ order, $s=\$ 10 /$ piece, $c_{b}=\$ 2 /$ unit $/$ year, $h_{m}=0.1 /$ year, $I_{p}=0.06, I_{e}=0.04$, and $D=5000 \times v^{-1.5}$ pieces/year. Table 1 shows the optimal replenishment cycle, order quantity, selling price, demand, and net profit for $M \epsilon$ $\{10,15,30,45,60\}$ days. As the results show, when the delay 
TABLE 2: The results of Example 2 for $M=10$.

\begin{tabular}{|c|c|c|c|c|c|c|c|}
\hline Parameter & Value & & $T$ (days) & $Q$ (units) & $v(\$)$ & $D$ (units/year) & NP (\$) \\
\hline \multirow{15}{*}{$A$} & \multirow{3}{*}{30} & GA-One-level & 45.97 & 3828.60 & 30.0223 & 30395.21 & 608243.63 \\
\hline & & CS-One-level & 33.86 & 2821.24 & 30.0103 & 30413.33 & 608261.92 \\
\hline & & CS-Traditional & 48.27 & 4019.74 & 30.0224 & 30394.97 & 608126.60 \\
\hline & \multirow{3}{*}{40} & GA-One-level & 54.93 & 4574.64 & 30.0226 & 30394.67 & 608153.44 \\
\hline & & CS-One-level & 43.85 & 3653.42 & 30.0162 & 30404.41 & 608167.98 \\
\hline & & CS-Traditional & 55.74 & 4641.77 & 30.0259 & 30389.70 & 608056.41 \\
\hline & \multirow{3}{*}{50} & GA-One-level & 57.41 & 4779.24 & 30.0291 & 30384.82 & 608086.72 \\
\hline & & CS-One-level & 51.97 & 4328.51 & 30.0206 & 30397.70 & 608091.80 \\
\hline & & CS-Traditional & 62.33 & 5189.82 & 30.0289 & 30385.06 & 607994.59 \\
\hline & \multirow{3}{*}{60} & GA-One-level & 63.30 & 5271.15 & 30.0256 & 30390.19 & 608023.33 \\
\hline & & CS-One-level & 58.98 & 4911.71 & 30.0243 & 30392.13 & 608026.00 \\
\hline & & CS-Traditional & 68.29 & 5685.33 & 30.0317 & 30380.87 & 607938.70 \\
\hline & \multirow{3}{*}{70} & GA-One-level & 67.31 & 5604.17 & 30.0290 & 30385.02 & 607966.54 \\
\hline & & CS-One-level & 65.24 & 5432.70 & 30.0275 & 30387.27 & 607967.23 \\
\hline & & CS-Traditional & 73.77 & 6141.03 & 30.0342 & 30377.01 & 607887.32 \\
\hline \multirow{15}{*}{$\rho$} & \multirow{3}{*}{0.70} & GA-One-level & 49.30 & 4089.80 & 30.1175 & 30251.54 & 607622.01 \\
\hline & & CS-One-level & 28.06 & 2336.10 & 30.0307 & 30382.35 & 607788.54 \\
\hline & & CS-Traditional & 35.98 & 2993.27 & 30.0501 & 30352.91 & 607565.54 \\
\hline & \multirow{3}{*}{0.75} & GA-One-level & 51.46 & 4268.38 & 30.1072 & 30267.01 & 607735.61 \\
\hline & & CS-One-level & 31.39 & 2613.57 & 30.0295 & 30384.27 & 607842.23 \\
\hline & & CS-Traditional & 39.42 & 3279.55 & 30.0458 & 30359.53 & 607653.97 \\
\hline & \multirow{3}{*}{0.80} & GA-One-level & 52.13 & 4333.90 & 30.0611 & 30336.43 & 607852.03 \\
\hline & & CS-One-level & 35.72 & 2974.51 & 30.0274 & 30387.36 & 607908.43 \\
\hline & & CS-Traditional & 44.07 & 3667.42 & 30.0409 & 30366.87 & 607751.80 \\
\hline & \multirow{3}{*}{0.85} & GA-One-level & 53.26 & 4433.41 & 30.0330 & 30378.87 & 607967.76 \\
\hline & & CS-One-level & 41.88 & 3487.49 & 30.0245 & 30391.72 & 607989.66 \\
\hline & & CS-Traditional & 50.89 & 4235.89 & 30.0354 & 30375.19 & 607862.85 \\
\hline & \multirow{3}{*}{0.90} & GA-One-level & 57.41 & 4779.24 & 30.0291 & 30384.82 & 608086.72 \\
\hline & & CS-One-level & 51.97 & 4328.51 & 30.0206 & 30397.70 & 608091.80 \\
\hline & & CS-Traditional & 62.33 & 5189.82 & 30.0289 & 30385.06 & 607994.59 \\
\hline \multirow{15}{*}{$I_{p}$} & \multirow{3}{*}{0.04} & GA-One-level & 61.29 & 5103.49 & 30.0276 & 30387.09 & 608092.04 \\
\hline & & CS-One-level & 52.90 & 4406.68 & 30.0202 & 30398.26 & 608100.44 \\
\hline & & CS-Traditional & 63.46 & 5283.68 & 30.0284 & 30385.84 & 608004.95 \\
\hline & \multirow{3}{*}{0.05} & GA-One-level & 56.99 & 4746.27 & 30.0225 & 30394.83 & 608092.76 \\
\hline & & CS-One-level & 52.42 & 4366.20 & 30.0204 & 30397.97 & 608096.00 \\
\hline & & CS-Traditional & 62.87 & 5235.08 & 30.0287 & 30385.44 & 607999.63 \\
\hline & \multirow{3}{*}{0.06} & GA-One-level & 57.41 & 4779.24 & 30.0291 & 30384.82 & 608086.72 \\
\hline & & CS-One-level & 51.97 & 4328.51 & 30.0206 & 30397.70 & 608091.80 \\
\hline & & CS-Traditional & 62.33 & 5189.82 & 30.0289 & 30385.06 & 607994.59 \\
\hline & \multirow{3}{*}{0.07} & GA-One-level & 58.15 & 4840.28 & 30.0334 & 30407.61 & 608081.51 \\
\hline & & CS-One-level & 51.55 & 4293.32 & 30.0208 & 30397.45 & 608087.80 \\
\hline & & CS-Traditional & 61.83 & 5147.57 & 30.0292 & 30384.71 & 607989.80 \\
\hline & \multirow{3}{*}{0.08} & GA-One-level & 58.32 & 4855.45 & 30.0287 & 30385.48 & 608075.62 \\
\hline & & CS-One-level & 51.15 & 4260.38 & 30.0209 & 30397.21 & 608084.01 \\
\hline & & CS-Traditional & 61.35 & 5108.04 & 30.0294 & 30384.37 & 607985.25 \\
\hline
\end{tabular}


TABLe 2: Continued.

\begin{tabular}{|c|c|c|c|c|c|c|c|}
\hline Parameter & Value & & $T$ (days) & $Q$ (units) & $v(\$)$ & $D$ (units/year) & $\mathrm{NP}(\$)$ \\
\hline \multirow{10}{*}{$I_{e}$} & \multirow{2}{*}{0.02} & GA-One-level & 62.84 & 5232.03 & 30.0276 & 30387.07 & 608036.64 \\
\hline & & CS-One-level & 57.38 & 4778.64 & 30.0250 & 30390.97 & 608040.99 \\
\hline & \multirow{2}{*}{0.03} & GA-One-level & 58.90 & 4904.98 & 30.0234 & 30393.46 & 608063.15 \\
\hline & & CS-One-level & 54.74 & 4559.14 & 30.0229 & 30394.21 & 608065.76 \\
\hline & \multirow{2}{*}{0.04} & GA-One-level & 57.41 & 4779.24 & 30.0291 & 30384.82 & 608086.72 \\
\hline & & CS-One-level & 51.97 & 4328.51 & 30.0206 & 30397.70 & 608091.80 \\
\hline & \multirow[t]{2}{*}{0.05} & GA-One-level & 55.00 & 4579.68 & 30.0269 & 30388.21 & 608112.95 \\
\hline & & CS-One-level & 49.04 & 4084.84 & 30.0181 & 30401.50 & 608119.30 \\
\hline & \multirow{2}{*}{0.06} & GA-One-level & 55.54 & 4626.30 & 30.0194 & 30399.52 & 608136.73 \\
\hline & & CS-One-level & 45.92 & 3825.66 & 30.0153 & 30405.69 & 608148.56 \\
\hline
\end{tabular}

payment period increases, the manufacturer's total cycle time and selling price decrease, while his net profit increases. This implies that longer credit period provided by the supplier increases the demand rate.

Example 2. This example pursues three major objectives. Firstly, it compares the results obtained by cuckoo search algorithm with those of genetic algorithm. Secondly, the proposed one-level trade credit is compared with the traditional inventory system, and thirdly, the effects of main parameters on the optimal solutions are analyzed. Except the given parameters in Table 2, the parameter values are equal to those mentioned in Example 1.

As bold numbers in Table 2 illustrates, cuckoo search algorithm obtains better results than genetic algorithm and also between the traditional inventory system and one-level trade credit, the latter is more profitable to the buyer. Besides, the results show that higher setup cost $(A)$ and capital opportunity cost $\left(I_{p}\right)$ would cause a higher value of selling price $(v)$ and lower net profit value. However, when the manufacturer's capacity utilization $(\rho)$ and interest earned rate $\left(I_{e}\right)$ increase, there would be a decrease in the selling price and an increase in his total net profit.

\section{Conclusions and Future Research}

This paper presents an inventory model under trade credit contract, where the manufacturer is allowed to delay paying to the supplier until a predefined period. To adapt the model with the real world, it is assumed that (I) the manufacturer's selling price may be different from his purchasing cost, (II) the replenishment rate is finite, (III) as in many practical situations, the shortages are included in the model, and (IV) the goods start deteriorating after being produced. Within the EPQ framework, the manufacturer's model is formulated and a metaheuristic algorithm, cuckoo search, is applied to determine his proper replenishment strategy. Furthermore, numerical examples are carried out to demonstrate that cuckoo search algorithm is more efficient than genetic algorithm and show the effectiveness of trade credit over the traditional inventory system. These examples are also utilized to analyze the sensitivity of the parameters on manufacturer's replenishment policy and his net profit.

Future research on this problem will focus on a twolevel trade credit, where even the manufacturer offers delay period to his customers. Moreover, the inventory system of the supplier would be formulated to model the integrated supplier-manufacturer inventory system and find the supply chain's best replenishment policy. There is another valuable possibility for developing this study which is considering the effects of competitive market, such as the competitors' selling price, on the manufacturer's decision making.

\section{Conflict of Interests}

The authors declare that there is no conflict of interests regarding the publication of this paper.

\section{Acknowledgments}

This research was supported by Universiti Putra Malaysia. Moreover, the authors would like to thank the anonymous reviewers for their valuable suggestions and comments which helped to improve the quality of the paper.

\section{References}

[1] D. Piasecki, "Consignment inventory: what is it and when does it make sense to use it?" White Paper, Inventory Operations Consulting, Kenosha, Wis, USA, 2004.

[2] Z. Molamohamadi, M. Rezaeiahari, and N. Ismail, "Consignment inventory: review and critique of literature," Journal of Basic and Applied Scientific Research, vol. 3, no. 6, pp. 707-714, 2013.

[3] C. W. Haley and R. C. Higgins, "Inventory policy and trade credit financing," Management Science, vol. 20, no. 4, pp. 464471, 1973.

[4] S. K. Goyal, "Economic order quantity under conditions of permissible delay in payments," The Journal of the Operational Research Society, vol. 36, no. 4, pp. 335-338, 1985.

[5] S. P. Aggarwal and C. K. Jaggi, "Ordering policies of deteriorating items under permissible delay in payments," The Journal of the Operational Research Society, vol. 46, no. 5, pp. 658-662, 1995. 
[6] A. M. M. Jamal, B. R. Sarker, and S. Wang, "An ordering policy for deteriorating items with allowable shortage and permissible delay in payment," The Journal of the Operational Research Society, vol. 48, no. 8, pp. 826-833, 1997.

[7] B. R. Sarker, A. M. M. Jamal, and S. Wang, "Supply chain models for perishable products under inflation and permissible delay in payment," Computers \& Operations Research, vol. 27, no. 1, pp. 59-75, 2000.

[8] H.-J. Chang and C.-Y. Dye, "An inventory model for deteriorating items with partial backlogging and permissible delay in payments," International Journal of Systems Science, vol. 32, no. 3, pp. 345-352, 2001.

[9] J.-T. Teng, "On the economic order quantity under conditions of permissible delay in payments," The Journal of the Operational Research Society, vol. 53, no. 8, pp. 915-918, 2002.

[10] K.-J. Chung and Y.-F. Huang, "The optimal cycle time for EPQ inventory model under permissible delay in payments," International Journal of Production Economics, vol. 84, no. 3, pp. 307-318, 2003.

[11] Y.-F. Huang, "Optimal retailer's ordering policies in the EOQ model under trade credit financing," The Journal of the Operational Research Society, vol. 54, no. 9, pp. 1011-1015, 2003.

[12] C.-T. Chang, L.-Y. Ouyang, and J.-T. Teng, "An EOQ model for deteriorating items under supplier credits linked to ordering quantity," Applied Mathematical Modelling, vol. 27, no. 12, pp. 983-996, 2003.

[13] C.-T. Chang and J.-T. Teng, "Retailer's optimal ordering policy under supplier credits," Mathematical Methods of Operations Research, vol. 60, no. 3, pp. 471-483, 2004.

[14] J.-T. Teng, C.-T. Chang, and S. K. Goyal, "Optimal pricing and ordering policy under permissible delay in payments," International Journal of Production Economics, vol. 97, no. 2, pp. 121-129, 2005.

[15] Y.-F. Huang, "Retailer's inventory policy under supplier's partial trade credit policy," Journal of the Operations Research Society of Japan, vol. 48, no. 3, pp. 173-182, 2005.

[16] L.-Y. Ouyang, J.-T. Teng, and L.-H. Chen, "Optimal ordering policy for deteriorating items with partial backlogging under permissible delay in payments," Journal of Global Optimization, vol. 34, no. 2, pp. 245-271, 2006.

[17] L.-H. Chen and L.-Y. Ouyang, "Fuzzy inventory model for deteriorating items with permissible delay in payment," Applied Mathematics and Computation, vol. 182, no. 1, pp. 711-726, 2006.

[18] L.-Y. Ouyang, K.-S. Wu, and C.-T. Yang, "A study on an inventory model for non-instantaneous deteriorating items with permissible delay in payments," Computers \& Industrial Engineering, vol. 51, no. 4, pp. 637-651, 2006.

[19] Y.-F. Huang, "Optimal retailer's replenishment decisions in the EPQ model under two levels of trade credit policy," European Journal of Operational Research, vol. 176, no. 3, pp. 1577-1591, 2007.

[20] J.-J. Liao, "An EOQ model with noninstantaneous receipt and exponentially deteriorating items under two-level trade credit," International Journal of Production Economics, vol. 113, no. 2, pp. 852-861, 2008.

[21] K.-J. Chung and C.-K. Huang, "An ordering policy with allowable shortage and permissible delay in payments," Applied Mathematical Modelling, vol. 33, no. 5, pp. 2518-2525, 2009.

[22] F. Hu and D. Liu, "Optimal replenishment policy for the EPQ model with permissible delay in payments and allowable shortages," Applied Mathematical Modelling, vol. 34, no. 10, pp. 3108-3117, 2010.
[23] J. Min, Y.-W. Zhou, and J. Zhao, "An inventory model for deteriorating items under stock-dependent demand and twolevel trade credit," Applied Mathematical Modelling, vol. 34, no. 11, pp. 3273-3285, 2010.

[24] K.-J. Chung, “The EPQ model under conditions of two levels of trade credit and limited storage capacity in supply chain management," International Journal of Systems Science, vol. 44, no. 9, pp. 1675-1691, 2013.

[25] Y.-J. Lin, L.-Y. Ouyang, and Y.-F. Dang, "A joint optimal ordering and delivery policy for an integrated supplier-retailer inventory model with trade credit and defective items," Applied Mathematics and Computation, vol. 218, no. 14, pp. 7498-7514, 2012.

[26] J.-T. Teng, J. Min, and Q. Pan, "Economic order quantity model with trade credit financing for non-decreasing demand," Omega, vol. 40, no. 3, pp. 328-335, 2012.

[27] P. Guchhait, M. K. Maiti, and M. Maiti, “Two storage inventory model of a deteriorating item with variable demand under partial credit period," Applied Soft Computing, vol. 13, no. 1, pp. 428-448, 2013.

[28] A. A. Taleizadeh, D. W. Pentico, M. S. Jabalameli, and M. Aryanezhad, "An EOQ model with partial delayed payment and partial backordering," Omega, vol. 41, no. 2, pp. 354-368, 2013.

[29] J. C. P. Yu, "A collaborative strategy for deteriorating inventory system with imperfect items and supplier credits," International Journal of Production Economics, vol. 143, no. 2, pp. 403-409, 2013.

[30] Y. He and H. Huang, "Two-level credit financing for noninstantaneous deterioration items in a supply chain with downstream credit-linked demand," Discrete Dynamics in Nature and Society, vol. 2013, Article ID 917958, 22 pages, 2013.

[31] C. K. Jaggi, S. K. Goyal, and S. K. Goel, "Retailer's optimal replenishment decisions with credit-linked demand under permissible delay in payments," European Journal of Operational Research, vol. 190, no. 1, pp. 130-135, 2008.

[32] X.-S. Yang and S. Deb, "Cuckoo search via Lévy flights", in Proceedings of the World Congress on Nature \& Biologically Inspired Computing (NaBIC '09), pp. 210-214, Coimbatore, India, December 2009.

[33] D. E. Goldberg, Genetic Algorithms in Search, Optimization and Machine Learning, Addison-Wesley, 1989.

[34] X. Yang, "Cuckoo search," in Nature-Inspired Metaheuristic Algorithms: Second Edition, X. Yang, Ed., pp. 105-115, Luniver Press, Forme, UK, 2nd edition, 2010.

[35] P. Zhao and H. Li, "Opposition-based Cuckoo search algorithm for optimization problems," in Proceedings of the 5th International Symposium on Computational Intelligence and Design (ISCID '12), vol. 1, pp. 344-347, Hangzhou, China, October 2012.

[36] C.-H. Ho, "The optimal integrated inventory policy with priceand-credit-linked demand under two-level trade credit," Computers \& Industrial Engineering, vol. 60, no. 1, pp. 117-126, 2011. 


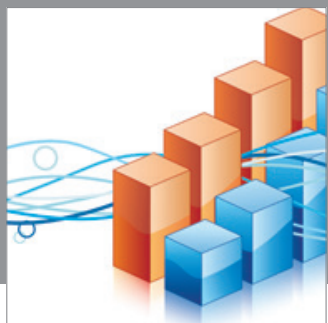

Advances in

Operations Research

mansans

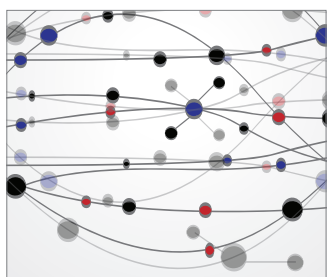

The Scientific World Journal
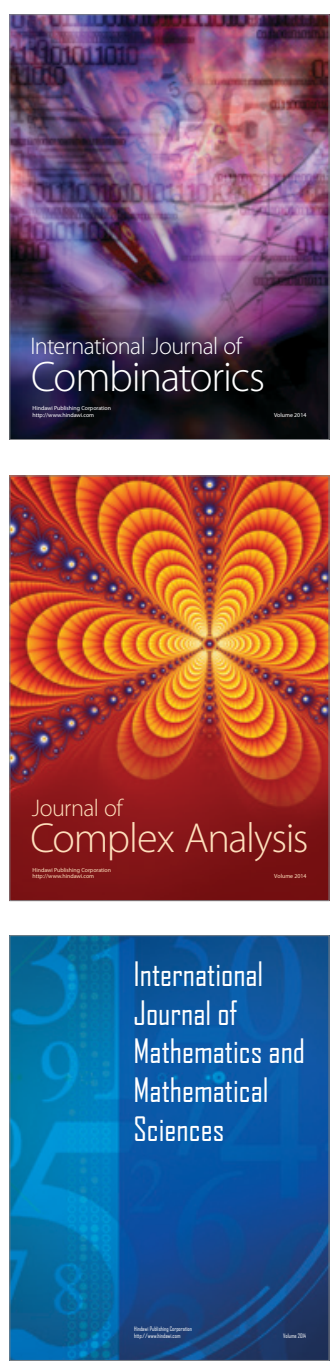
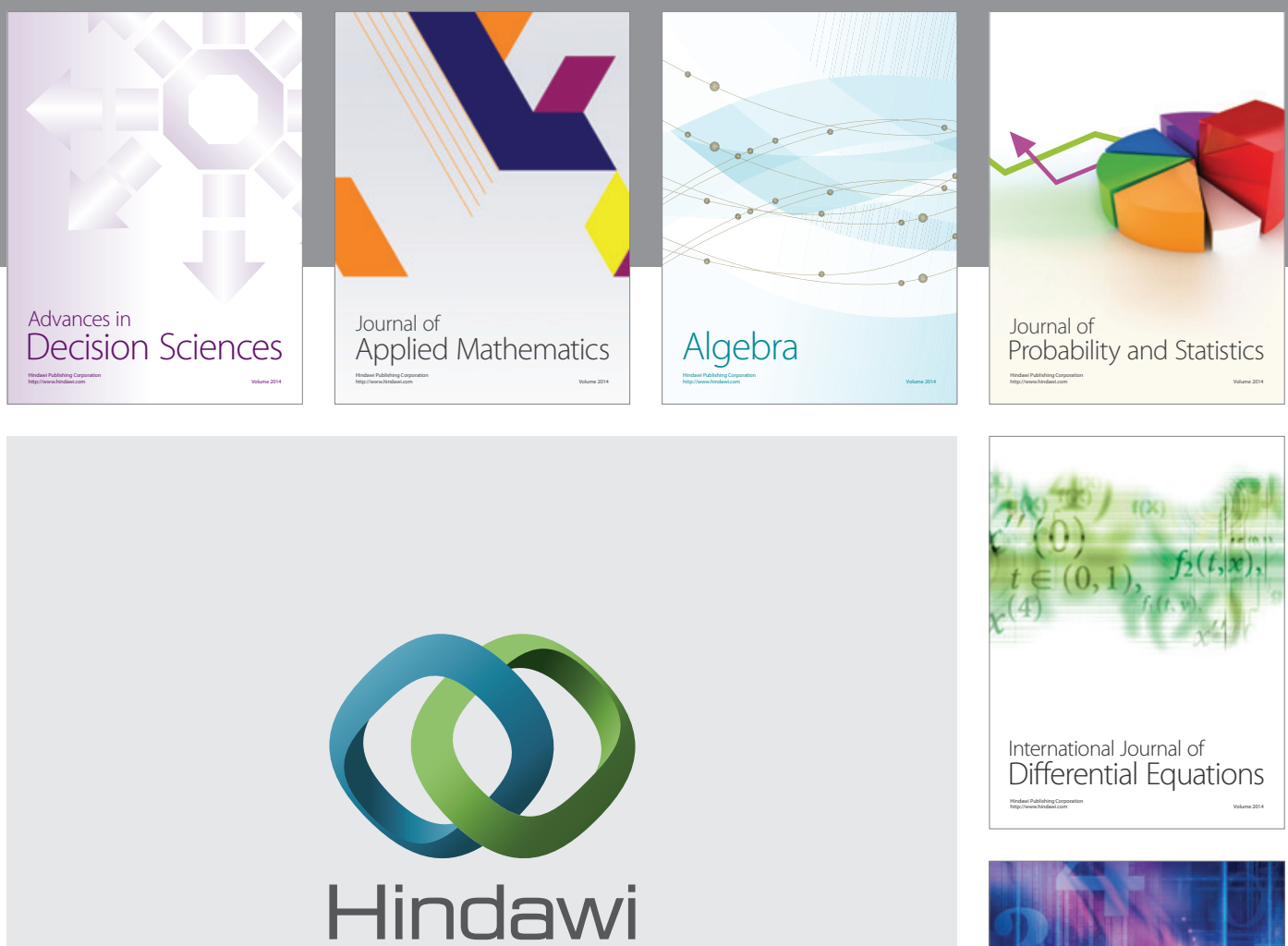

Submit your manuscripts at http://www.hindawi.com
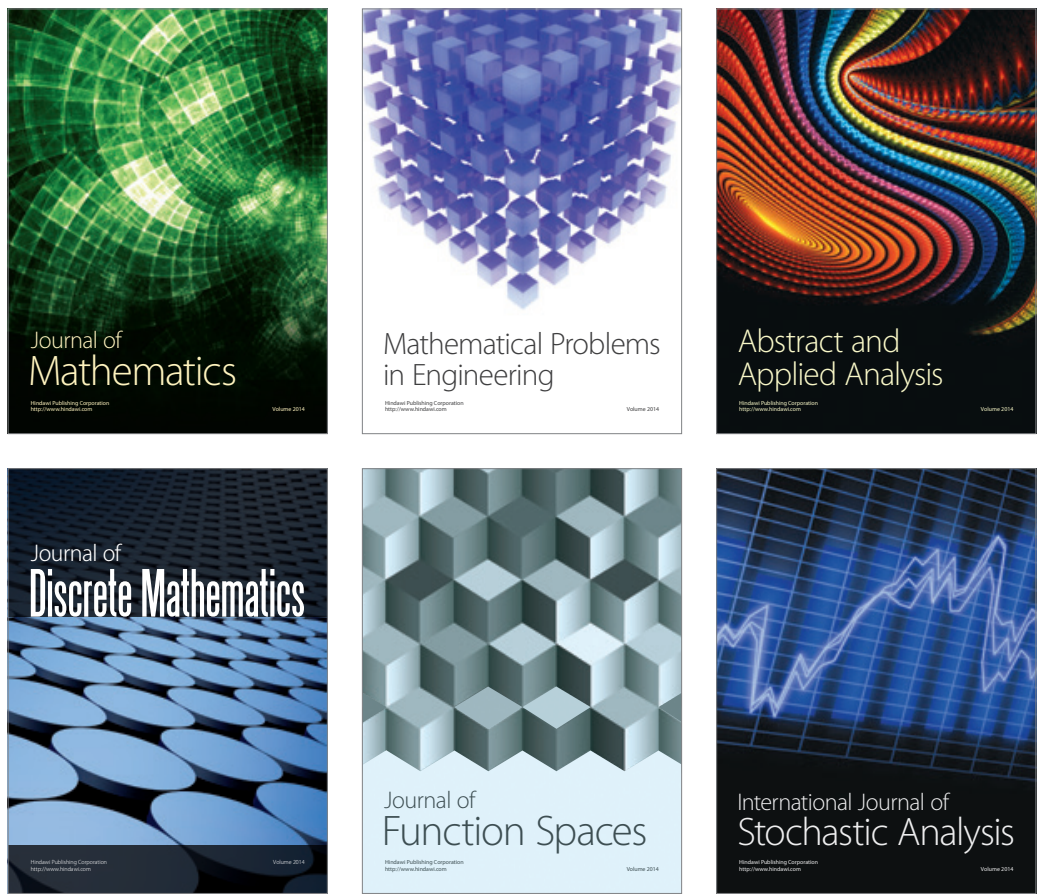

Journal of

Function Spaces

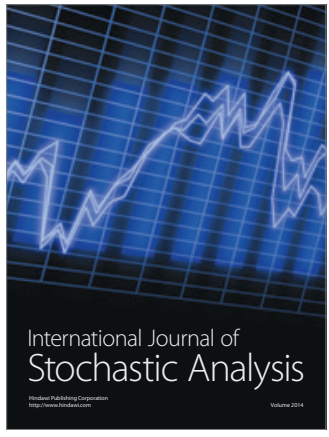

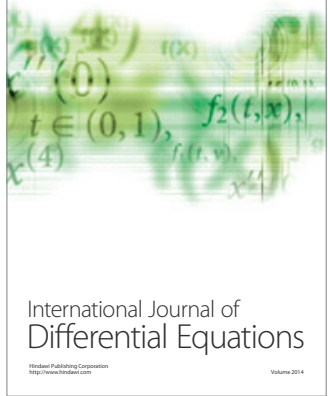
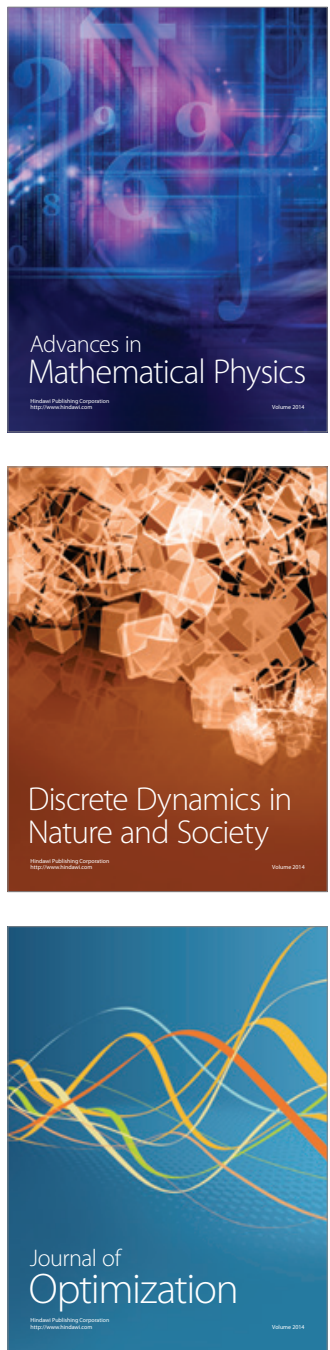